\title{
Structure and Peroxidase Activity of Ferric Streptomyces clavuligerus orf10-encoded Protein P450CLA: UV-Visible, CD, MCD and EPR Spectroscopic Characterization
}

\author{
Leandro S. Goto, ${ }^{*, a, b}$ Carlos O. Hokka, ${ }^{a}$ José F. Lima, ${ }^{b}$ Tatiana Prieto, ${ }^{b}$ \\ Ana Paula U. Araújo, ${ }^{b}$ Iseli L. Nantes ${ }^{*, c}$ and Otaciro R. Nascimento ${ }^{*, b, c}$ \\ ${ }^{a}$ Grupo de Engenharia Bioquímica, Departamento de Engenharia Química, \\ Universidade Federal de São Carlos, 13565-905 São Carlos-SP, Brazil
}

${ }^{b}$ Grupo de Biofísica Molecular "Sérgio Mascarenhas", Instituto de Física de São Carlos, Universidade de São Paulo, CP 369, 13560-970 São Carlos-SP, Brazil

\author{
'Grupo de Nanoestruturas para Biologia e Materiais Avançados, Centro de Ciências Naturais e Humanas, \\ Universidade Federal do ABC, 09210-170 Santo André-SP, Brazil
}

\begin{abstract}
O presente trabalho reporta a caracterização espectroscópica por absorção UV-visível, dicroísmo circular magnético (MCD) e ressonância paramagnética eletrônica (EPR) da proteína recombinante do tipo P450-canfora (P450CAM) codificada pela orf10 de Streptomyces clavuligerus (P450CLA) expressa por Escherichia coli Rosetta na forma nativa e associada a ligantes externos contendo os grupos $\beta$-lactamato, oxazol e derivado de alquilamina (álcool) do ácido clavulâmico. Considerando a diversidade de aplicações da enzima $\mathrm{P} 450$, sua reatividade com terc-butil-hidroperóxido (terc-BuOOH) foi caracterizada. O grupo heme da P450CLA apresenta-se covalentemente ligado e exibe características espectrais de UV-visível, CD e MCD de P450CAM, incluindo a banda Soret em $450 \mathrm{~nm}$ proveniente do complexo ferroso-CO. P450CLA foi convertido em espécies de valência alta pelo terc-BuOOH e promoveu cisão homolítica da ligação $\mathrm{O}-\mathrm{O}$. O perfil radicalar da reação foi terc-butiloxil como radical primário e metil e butilperoxil como radicais secundários. Os radicais metil e butilperoxil resultaram respectivamente da cisão- $\beta$ do radical alcoxil e da reação do radical metil com oxigênio molecular.
\end{abstract}

The present study reports the spectroscopic characterization by UV-visible absorption spectroscopy, magnetic circular dichroism (MCD) and electron paramagnetic resonance (EPR) of the recombinant orf10-encoded P450-camphor like protein (P450CLA) of Streptomyces clavuligerus expressed in Escherichia coli Rosetta in the native form and associated to external ligands containing the $\beta$-lactam, oxazole and alkylamine-derived (alcohol) moieties of the clavulamic acid. Considering the diversity of potential applications for the enzyme, the reactivity with tert-butylhydroperoxide (tert-BuOOH) was also characterized. P450CLA presents a covalently bound heme group and exhibited the UV-visible, CD and MCD spectral features of P450CAM including the fingerprint Soret band at $450 \mathrm{~nm}$ generated by the ferrous CO-complex. P450CLA was converted to high valence species by tert-BuOOH and promoted homolytic scission of the $\mathrm{O}-\mathrm{O}$ bond. The radical profile of the reaction was tert-butyloxyl as primary and methyl and butylperoxyl as secondary radicals. The secondary methyl and butylperoxyl radicals resulted respectively from the $\beta$-scission of the alkoxyl radical and from the reaction of methyl radical with molecular oxygen.

Keywords: cytochrome P450, orf10, peroxidase activity, magnetic circular dichroism, electron paramagnetic resonance, spin trapping

\section{Introduction}

Based on the specific sequence homology, the orf10 gene of Streptomyces clavuligerus has been assigned

*e-mail: 1sg@if.sc.usp.br, ilnantes@ufabc.edu.br, ciro@if.sc.usp.br to potentially encoding for a cytochrome P450-like enzyme. S. clavuligerus orf10 knockout mutant lacks the production of clavulanic acid, which has led to the proposal that orf10 plays a yet uncharacterized role in the clavulanic acid biosynthetic pathway. ${ }^{1-5}$ Clavulanic acid is a secondary metabolite that has a fused bicyclic 
$\beta$-lactam/oxazolidine ring system similar to penicillin. ${ }^{6}$ Despite sharing the $\beta$-lactam ring structure, clavulanic acid has negligible antibiotic activity. However, this structural similarity to penicillin allows the molecule to act as a competitive inhibitor of secreted $\beta$-lactamases and hence restores the activity of common $\beta$-lactam antibiotics against $\beta$-lactam-resistent bacteria. In this regard, one of the major obstacles to the demonstration of orf10's involvement in the clavulanic acid pathway is that the substrates for orf10-encoded protein catalysis are unavailable. Another difficulty resides in the predicted, widely accepted involvement of additional proteins in the catalysis. The $S$. clavuligerus class I P450 orf10-encoded protein (P450CLA) ${ }^{4}$ is denoted as CYP105M1.-9 The P450 superfamily is poorly conserved and only three residues are almost invariantly conserved, including a totally conserved cysteine that serves as the fifth ligand for the heme iron, and the EXXR motif that is highly conserved. ${ }^{10}$

Considering the interest in the potential therapeutic use of clavulanic acid and a diversity of potential applications for P450 proteins, a better characterization of the orf10-encoded protein is relevant. In the present study, for the first time, electronic absorption spectroscopy, circular dichroism (CD), magnetic circular dichroism (MCD) and electron paramagnetic resonance (EPR) were used to corroborate that orflo encodes a functional cytochrome P450-like enzyme putatively required for the synthesis of clavulanic acid.

\section{Experimental}

\section{General procedures}

Streptomyces clavuligerus ATCC 27064 was purchased from the American Type Culture Collection (Manassas, VA) and stored at $-80{ }^{\circ} \mathrm{C}$ in $40 \%$ v/v glycerol. Custom oligonucleotides were provided by IDT (Integrated DNA Technologies, Coralville, IA). Restriction enzymes were obtained from Promega (Madison, WI). PCR reagents and cloning vectors were supplied by Fermentas (Glen Burnie, MD). Dimethylsulphoxide (DMSO), 5-aminolevulinic acid (ALA), sodium dithionite, tert-butyl-hydroperoxide (tert-BuOOH), clavulanic acid (potassium clavulanate), ampicillin, camphor, glycine, proline, histidine, glycyl-histidine, 3-amino-1,2,4-triazole, imidazole, histamine and 5,5-dimethyl-1-pyrroline $N$-oxide (DMPO) were purchased from Sigma (St. Louis, MO). Other reagents were of analytical grade or higher. Standard microbial and recombinant DNA techniques used throughout this work were previously described, ${ }^{11}$ or are detailed in the text.

Cloning, construction of expression systems, recombinant expression and protein purification

See online Supplementary Information (SI) section.

\section{Absorption spectroscopy}

Absorption UV-visible spectra were obtained at room temperature in a $500 \mu \mathrm{L}$ quartz cuvette $(1 \mathrm{~cm}$ light path length) loaded into a Hitachi U-2800 UV-vis spectrophotometer (Hitachi, Hitachi City, Ibaraki Prefecture). Spectra were measured from 700 to $350 \mathrm{~nm}$ and recorded in $1 \mathrm{~nm}$ intervals using a $500 \mu \mathrm{L}$ sample containing $17 \times 10^{-6} \mathrm{~mol} \mathrm{~L}^{-1}$ of protein in $100 \mathrm{mmol} \mathrm{L}^{-1} \mathrm{NaCl}$, $50 \mathrm{mmol} \mathrm{L}^{-1}$ Tris-HCl, $\mathrm{pH}$ 8.0. For the ferric water-bound form, the sample was scanned under the described conditions. The ferrous CO-complex was measured after anaerobic ( $\mathrm{N}_{2}$ environment) 5 min of mild bubbling with $\mathrm{CO}$, followed by the addition of a molar excess of sodium dithionite. The substrate sub-structural analogue binding complexes were measured in the ferric state and registered after arbitrary successive addition of each ligand solid salt to $500 \mu \mathrm{L}$ protein samples at $8 \times 10^{-6} \mathrm{~mol} \mathrm{~L}^{-1}$ until no appreciable spectral changes were seen. Later, the complexes were reduced to the ferrous forms by anaerobic addition of sodium dithionite.

The expected covalent attachment of heme iron to the peptide chain was tested by the incubation of the protein at strongly acid $\mathrm{pH}$, a condition in which no covalent heme iron detaches from the unfolded protein and precipitates at the bottom of the test tube. The electronic absorption spectrum of the hemeprotein was briefly measured at $\mathrm{pH} 8.0$ to ascertain the presence of $\mathrm{P} 450-\mathrm{CO}$ species, and then another electronic absorption spectrum was measured for the same protein at $\mathrm{pH} 2.0$. At $\mathrm{pH} 2.0$, no significant spectral change indicative of heme iron loss was detected in the sample before and after centrifugation (10 $\mathrm{min}$ at $400 \times$ g) consistent with covalently bound heme iron.

\section{Circular dichroism spectroscopy}

CD measurements were performed at room temperature using a J-720 (JASCO Inc., Easton, MD) spectropolarimeter and a $0.1 \mathrm{~cm}$ quartz cuvette. Two wavelength ranges were used depending on the targeted chromophore (the protein structure or the heme iron). For secondary structure determination, a $4 \times 10^{-6} \mathrm{~mol} \mathrm{~L}^{-1}$ protein solution in $50 \times 10^{-3} \mathrm{~mol} \mathrm{~L}^{-1}$ Tris- $\mathrm{HCl} \mathrm{pH} 8.0$ containing 
$50 \times 10^{-3} \mathrm{~mol} \mathrm{~L}^{-1} \mathrm{NaCl}$ and $10 \% \mathrm{v} / \mathrm{v}$ glycerol was measured in the far-UV wavelength range (250-195 nm) and recorded as an average of 8 scans at $100 \mathrm{~nm} \mathrm{~min}^{-1}$ using a $0.1 \mathrm{~nm}$ data pitch dump. Secondary and tertiary structural predictions were done using the CDPro software package. ${ }^{12-14}$ For heme iron measurements, a $0.13 \times 10^{-3} \mathrm{~mol} \mathrm{~L}^{-1}$ protein solution in $16 \times 10^{-3} \mathrm{~mol} \mathrm{~L}^{-1}$ sodium phosphate $\mathrm{pH} 7.4$ containing $50 \times 10^{-3} \mathrm{~mol} \mathrm{~L}^{-1} \mathrm{NaCl}$ was measured in the near-UV-visible range (700-350 $\mathrm{nm})$. Spectra were recorded as an average of 16 scans at $400 \mathrm{~nm} \mathrm{~min}{ }^{-1}$, collecting data points every $0.2 \mathrm{~nm}$, both with (MCD) and without a magnetic field of $860 \mathrm{mT}$.

Electron paramagnetic resonance (EPR) of heme iron in the absence and presence of tert- $\mathrm{BuOOH}$

Continuous wave EPR spectra were recorded at $-248{ }^{\circ} \mathrm{C}(25 \mathrm{~K})$ in a Bruker Elexsys line E-580 X-band spectrometer (Bruker, Billerica, MA) equipped with a standard rectangular cavity and an Oxford cryostat system containing liquid helium (Oxford Instruments, Abingdon, Oxfordshire). The microwave frequency was set to $9.47607 \mathrm{GHz}$, using $1 \mathrm{~mW}$ power and sweeping the magnetic field from 25 to $425 \mathrm{mT}$. A $50 \mu \mathrm{L}$ protein sample at a concentration of $250 \times 10^{-6} \mathrm{~mol} \mathrm{~L}^{-1}$ in $50 \times 10^{-3} \mathrm{~mol} \mathrm{~L}^{-1}$ Tris- $\mathrm{HCl} \mathrm{pH} 8.0$ containing $100 \times 10^{-3} \mathrm{~mol} \mathrm{~L}^{-1} \mathrm{NaCl}$ and $10 \% \mathrm{v} / \mathrm{v}$ glycerol was loaded into a quartz cell and frozen in liquid nitrogen prior to being measured. This measurement was set as the initial state. For scans at subsequent times, $30 \mu \mathrm{L}$ of aqueous $1.25 \mathrm{~mol} \mathrm{~L}-1$ tert-BuOOH, exceeding 3000 fold the tert-BuOOH/protein molar ratio, was added to the sample.

\section{Spin trapping EPR measurements}

EPR spectra were recorded at room temperature using a Varian E-109 spectrometer (Varian Inc., Palo Alto, CA) operating at $9.5091 \mathrm{GHz}$ in a rectangular cavity. DMPO was used as an EPR spin trap for the radical adducts formed on reacting tert-BuOOH with P450CLA. $50 \mu \mathrm{L}$ samples with $8 \times 10^{-6} \mathrm{~mol} \mathrm{~L}^{-1}$ protein in $50 \times 10^{-3} \mathrm{~mol} \mathrm{~L}^{-1}$ Tris- $\mathrm{HCl}$, pH 8.0 containing $100 \times 10^{-3} \mathrm{~mol} \mathrm{~L}^{-1} \mathrm{NaCl}$ and $10 \% \mathrm{v} / \mathrm{v}$ glycerol had separate additions of DMPO up to $160 \times 10^{-3} \mathrm{~mol} \mathrm{~L}^{-1}$ and $650 \times 10^{-3} \mathrm{~mol} \mathrm{~L}^{-1}$. Each sample was loaded into a flat quartz cell and the reactions were initiated by the addition of tert-BuOOH (up to $\left.375 \times 10^{-3} \mathrm{~mol} \mathrm{~L}^{-1}\right)$. After approximately $2 \mathrm{~min}$ of incubation following the addition of tert-BuOOH, EPR measurements were performed in the range 334-344 mT. Simulations were performed using the SimFonia computer program from Bruker.

\section{Results and Discussion}

The sequence of the S. clavuligerus orf10-encoded protein is consistent with a P450 enzyme and yielded a structured protein with covalently bound heme

As described in the Supplementary Information (SI) section, two oligonucleotides were synthesized as PCR primers to produce the engineered P450CLA-encoding DNA for expression experiments. According to the targeted DNA sequence, the PCR experiment should result in an amplification product with the mass (corresponding to about $1200 \mathrm{bp}$ ) that was effectively detected by $0.8 \%$ agarose TAE electrophoresis (data not shown). The full-length sequence of the cloned DNA fragment was identical to that expected (GenBank accession codes AY034175 and AAF85938). The protein sequence predicted from the DNA sequence was computationally analyzed. ${ }^{15,16}$ In the analyzed sequence, a cysteine-containing potential heme binding motif (FGHGMHQCLG) was found. Besides the one cysteine residue that is a totally conserved distal heme iron ligand, the well-conserved EXXR motif characteristic of P450s was also identifiable. The predicted primary sequence of the protein encoded by orf10 was aligned with CYP105A $1,{ }^{17}$ the closest BLAST ${ }^{18}$ match that has a solved structure (41\% identity), and with CYP101A1 (22\% identity), which is the most well-known bacterial P450 (P450CAM) (Figure S1).

The cloned PCR product was subcloned into the pET28a vector and transformed into $E$. coli Rosetta (DE3) for heterologous production of the orf10-encoded protein. As expected, recombinant CYP105M1 (herein named P450CLA) yielded an additional over expression band of approximately $45 \mathrm{kDa}$ (Figure S2). P450CLA was isolated from the crude soluble cell lysate using the IMAC (immobilized metal-ion affinity chromatography) procedure, and purified to homogeneity using ion-exchange chromatography (Figure S2). Native PAGE (polyacrylamide gel electrophoresis, PhastSystem, GE Healthcare) (not shown) and size-exclusion chromatography on a Superdex 200 (GE Healthcare) indicated that the purified protein was obtained as a monomer of the expected size (not shown). Purified P450CLA was injected into mice for the production of anti-CYP105M1 sera that was effective to recognize a protein with equivalent mass in immunoblotting assays performed with S. clavuligerus ATCC 27064 cell extract (not shown).

The presence of a covalently bound heme group was corroborated by a denaturation (see Experimental section) assay followed by centrifugation. The pellet did not contain protoporphyrn IX and the supernatant that remained 
exhibited electronic absorption spectrum with the Soret and Q bands typical of the hemeprotein (not shown).

Far-UV CD of the protein showed two negative bands peaking at 220 and $208 \mathrm{~nm}$ (Figure S3), indicating an $\alpha+\beta$ structured protein. Secondary and tertiary structure predictions were generated using CDPro. ${ }^{13,14}$ Predictions made using a 56-protein reference set confirmed the $\alpha+\beta$ spectrum class, and yielded $27 \%$ regular $\alpha$-helices, $18 \%$ distorted helices, $5 \%$ regular $\beta$-strands, $6 \%$ distorted strands, $17 \%$ turns and $27 \%$ unordered structures.

The orf10-encoded protein exhibited UV-visible and MCD spectral features of P450-CAM including the fingerprint Soret band at $450 \mathrm{~nm}$ by the ferrous CO-complex

The orf10-encoded P450CLA protein was analyzed by electronic absorption spectroscopy and exhibited spectral features consistent with a P450 protein. The features exhibited by the UV-visible absorbance spectrum of the P450CLA resting form matched totally those previously described for P450CAM isolated and purified from Pseudomonas putida: ${ }^{19}$ a Soret band maximum at $417 \mathrm{~nm}$ with $\varepsilon=62100 \mathrm{~mol}^{-1} \mathrm{~L} \mathrm{~cm}^{-1}, \mathrm{Q}_{\alpha}$ band peaking at $570 \mathrm{~nm}$, more intense than the $\mathrm{Q}_{\beta}$ band peaking at $536 \mathrm{~nm}$ and also a relatively well defined peak at $356 \mathrm{~nm}$ (Figure 1A).

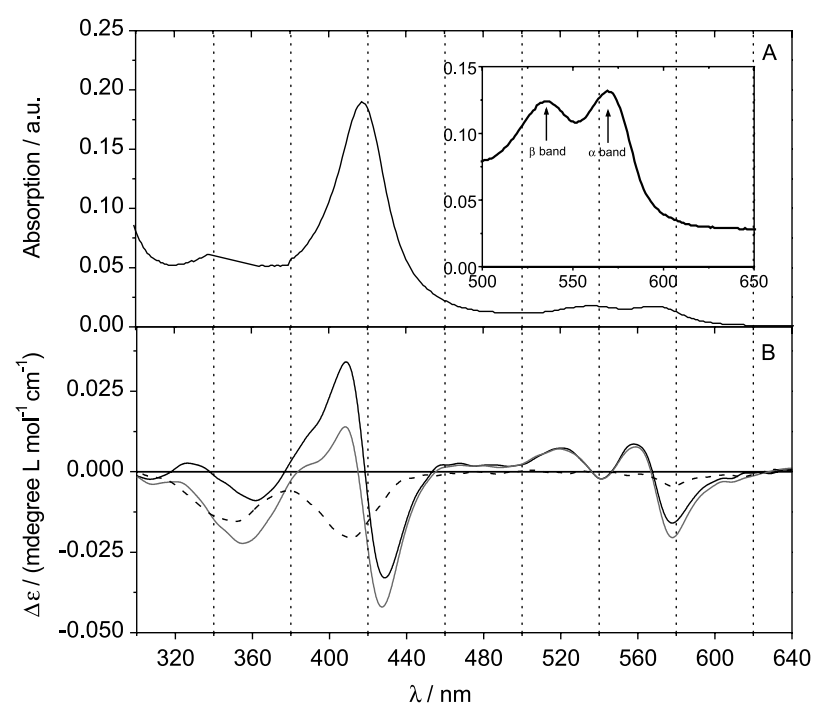

Figure 1. Spectroscopic characteristics of P450CLA. (A) Electronic absorption (insert: zooming of $\alpha$ and $\beta$ band regions) and (B) $C D$ (dashed line), MCD-CD (gray line) and MCD (black line) spectra of $15 \times 10^{-3} \mathrm{~mol} \mathrm{~L}^{-1} \mathrm{P} 450 \mathrm{CLA}$. The spectra were obtained as described in the Experimental section.

As expected for the complexes with transition metals exhibiting vacant d-orbitals that participate in charge transfer transitions, a complex MCD spectrum was obtained for P450CLA. In a hemeprotein, the presence of a partially filled set of d-orbitals results in ligand to metal and metal to ligand transitions that are responsible for the charge transfer bands (LMCT, MLCT) observed in both UV-visible and MCD spectra and, in addition, for the $\pi \rightarrow \pi^{*}$ bands. ${ }^{20,21}$ The room temperature MCD spectrum for the resting P450CLA heme closely matched that reported for P450CAM of $P$. putida ${ }^{19}$ The MCD spectrum of P450CLA (Figure 1B) obtained after the subtraction of CD signals presents a pair of oppositely signed MCD bands of nearly equal amplitude that peak at 427 and $409 \mathrm{~nm}$ with the zero crossing at the absorption maximum at $418 \mathrm{~nm}$. At longer weaker wavelengths, they are found as a positive band at $559 \mathrm{~nm}$ and a negative band at $579 \mathrm{~nm}$.

The derivative shape of MCD bands is normally indicative of a predominant contribution of a Faraday $A$ term, but, in the present condition, the slight distortion of the symmetrical $A$ term in a positive direction indicates an intermediate case in which a $B$ term is also present. Therefore, probably the spectrum results from the contribution of a set of degenerate metal d-orbitals split by the magnetic field (Zeeman effect) and associated with the mixing of an intermediate state $(|\mathrm{K}\rangle)$ with an excited state $(|\mathrm{J}\rangle)$ of the rhombically distorted porphyrin. The double spectral contribution becomes evident when comparing the CD spectra with the MCD spectra from which the CD signal was not subtracted. The comparison provides evidence that when the magnetic field is applied to the system, the contribution of a derivative shape becomes almost the absolute contribution after the CD signal was subtracted. ${ }^{21}$

In addition, the fingerprint of the P450 enzymes, i.e., the red shift of the Soret band to $450 \mathrm{~nm}$ observed for the ferrous CO-complex was obtained after sodium dithionite addition in P450CLA samples under $\mathrm{CO}$ atmosphere (Figure 2A). The red shift of the Soret band to $450 \mathrm{~nm}$ exhibited by the ferrous-CO-complex of P450CLA is the low energy component of a split Soret band system (the hyperporphyrin), ${ }^{22}$ in which the high energy component is near $370 \mathrm{~nm}$.

Although without a consensus for the identification of orbitals contributing for the mixing mechanism, these peculiar spectral features arise from orbital mixing. Similar to the MCD spectrum reported for P450CAM and similar proteins, ${ }^{19,23,24}$ the MCD spectrum of ferrous-CO-complex P450CLA presented a derivative shape band with zero crossing around $450 \mathrm{~nm}$ (Figure 2B). In contrast to the experimental conditions used for the UV-visible spectroscopic measurements, in which all of the P450CAM was in the complexed ferrous form, a significant amount of the P450CAM was in the non-complexed ferrous form for the experimental conditions used for the MCD spectral measurements. The cause is the higher concentration of 


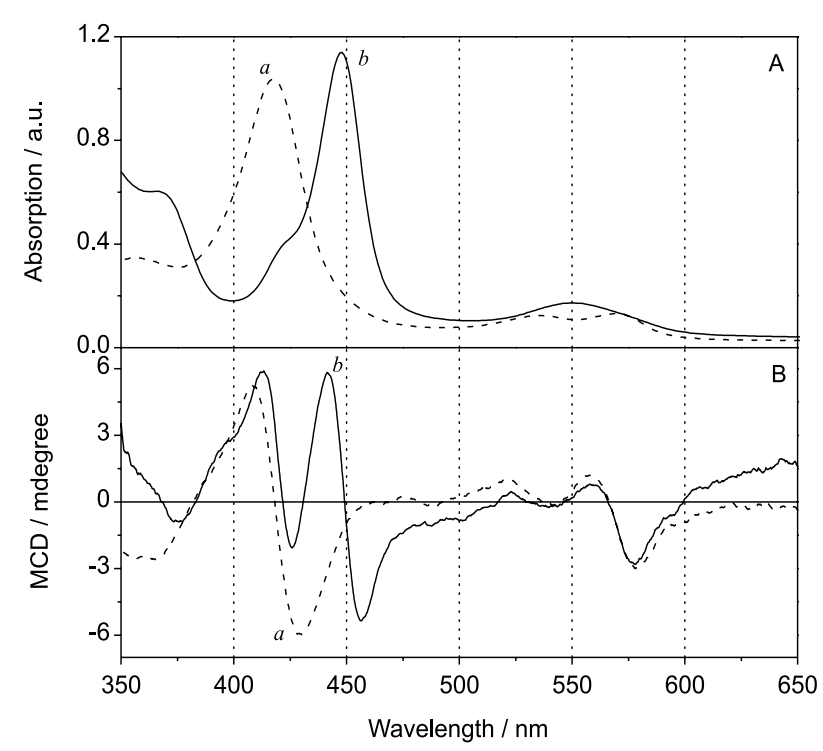

Figure 2. Spectroscopic characteristics of the ferrous CO-complex of P450CLA. (A) Alectronic absorption spectra of the resting form $(a)$ and of the ferrous CO-complex of P450CLA $(b)$ and (B) MCD spectrum of resting form $(a)$ and of the ferrous CO-complex with a reminiscent non CO-complex ferrous form $(b)$. The spectra were obtained as described in the Experimental section.

protein required for the MCD measurements in contrast to that required for the UV-visible measurements. Here, due to the limited solubility of $\mathrm{CO}$ in the buffer solution, not all of the protein is in the CO-complexed form. The partial conversion to CO-complex in the MCD experimental conditions precluded detection of a significant and confident MCD signal of the ferrous-CO-complex due to the overlap of bands.

As described above, the CD spectrum of P450CLA shows a negative Soret band with an absorption shape and does not exhibit the contribution of a derivative band shape that is added by the presence of a magnetic field. For P450CAM, a derivative shape band with zero crossing around $450 \mathrm{~nm}$ is present in the CD spectrum of the ferrousCO-complex in addition to the negative absorption shape band that remains present but blue shifted relative to that obtained for the resting form. The presence of a derivative $\mathrm{CD}$ band for the ferrous-CO-complex can be seen by the splitting of the degenerate d-orbital energy levels at zero field induced by $\mathrm{CO}$ binding of the heme iron axial ligand at the sixth coordination position ${ }^{25}$ (see in Figure 2B the significant reminiscent MCD signal of the ferrous form that remains present after $\mathrm{CO}$ purging).

According to Hanson et al. ${ }^{26}$ a charge transfer occurs from the lone pair p-orbital of the cysteinate sulfur to the porphyrin $\pi^{*}$-orbitals leading to the splitting of the doubly degenerate porphyrin $\pi-\pi^{*}$-orbital energy levels. However, according to Jung and Ristau, ${ }^{27}$ the split Soret band results from the charge-transfer transitions from an axial system consisting of cysteinate $\pi$-orbitals, $\mathrm{CO} \pi$-orbitals, and the $\mathrm{d} \pi$-orbitals of ferrous iron to the porphyrin $\pi^{*}$-orbitals mixed with the $\pi-\pi^{*}$ porphyrin transitions. Whatever the mechanism responsible for the split Soret band in the absence of $\mathrm{CO}$, the orbital split can be induced by the magnetic field (Zeeman effect) and the derivative shape band is observed only in the MCD spectra. According to the ligand field theory, the presence of $\mathrm{CO}$ induces degenerate orbital splitting and a derivative shape band is observed at zero field. In this regard, the comparison of ferric resting and ferrous CO-complex P450CLA spectra should also consider the redox state of heme iron. It is reported that the heme ligand acts as a very strong $\pi$-donor to $\mathrm{Fe}^{3+}$ and a weak $\pi$-acceptor from $\mathrm{Fe}^{2+}$. Upon going from $\mathrm{Fe}^{3+}$ to $\mathrm{Fe}^{2+}$, the d-orbitals increase in energy due to the decrease in $Z_{\text {eff, }}$ and this leads to the enhancement of back-bonding, but yet low as compared with $\sigma$-donation from the porphyrin ring. For the low-spin $\mathrm{Fe}^{2+}$ heme complex, the effects of strong $\sigma$-donation by the porphyrin are evidenced by the $0.7 \mathrm{eV}$ shift of the Fe L-edge spectrum of the $\mathrm{Fe}^{2+}$ heme complex to higher energy relative to the Fe L-edge spectrum of the $\mathrm{Fe}^{2+}$ non-heme complex. ${ }^{28}$

The P450CLA-exhibited affinity to molecules containing $\beta$-lactamic, oxazole and alkyl amine moieties is consistent with a putative participation in the clavulanic acid biosynthesis

Considering that $S$. clavuligerus knockouts of orf10 failed to produce clavulanic acid, the gene is a candidate for a protein which is necessary for the synthesis of clavulanic acid. The missing steps in the clavulanic acid synthesis pathway when this protein is absent need to be identified. The first four steps of the clavulanic acid anabolism have been elucidated, as well as the last, in which clavaldehyde is converted to clavulanic acid.

However, the steps responsible for the conversion of clavaminic acid to clavaldehyde remain to be elucidated and involve oxidative deamination and epimerization reactions (equation 1) requiring a P450-like enzyme such as the one encoded by the orf 10 .

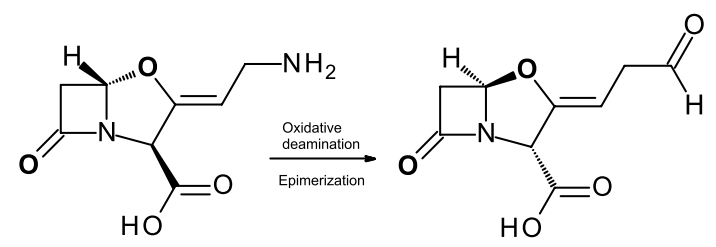

Therefore, a series of compounds containing $\beta$-lactam, oxazole and alkyl amine moieties, which compose the 
clavulanic acid structure (Figure S4), were probed for the capacity to promote P450CLA spectral changes that are indicative of coordination with heme iron.

The spectral changes observed in the presence of the probed compounds indicate that, similarly to P450CLA, the orf10-encoded protein exhibits high affinity for the imidazole ring and this moiety induces the spectral changes promoted by the exogenous ligands in which it is present. Interestingly, similar spectral features were observed in the presence of ampicillin, in which thiazole, and not imidazole, was present. In addition, it was observed that alkylamino groups not associated to a cyclic structure promoted spectral changes in P450CAM different from those observed when it was associated to the imidazole moiety. Taken together, these results suggest that the oxazole moiety may be responsible for the affinity of a precursor of clavaldehyde for the P450CAM heme iron. The spectral changes were observed before and after addition of dithionite, except for glycylhistidine, which did not exhibit affinity for ferrous P450CAM.

The spectral changes observed for P450CAM in the presence of exogenous ligands before and after dithionite addition are summarized in Table S1.

The orf10-encoded protein is converted to a high valence state by tert-butylhydroperoxide and promotes homolytic scission of the $\mathrm{O}-\mathrm{O}$ bond

Based on the previous report ${ }^{29}$ about the capacity of $\mathrm{P} 450$ to promote cleavage of peroxides, the reactivity of P450CLA with tert-BuOOH was also investigated (Figures 3 and 4). EPR measurements of the resting protein (Figure 3, line a and gray line for the simulated spectrum) exhibited an anisotropic EPR signal in the $\mathrm{g}=2$ region ( $\mathrm{g}$ values $=2.417,2.245,1.919)$, confirming that most of the P450CLA iron had spin state $\mathrm{S}=1 / 2,{ }^{29}$ which is consistent with P450 cytochrome.

Organic hydroperoxides could support several P450-catalyzed reactions by providing oxidation equivalents derived from the scission of the peroxide $\mathrm{O}-\mathrm{O}$ bond. The study of the reaction of cumene hydroperoxide with rabbit microsomal P450 demonstrated that P450 promotes homolytic scission of $\mathrm{O}-\mathrm{O}$ bond with generation of alkoxyl radical as the primary free radical species. Methyl radical was detected as secondary as well as peroxyl radical whose formation was dependent of the availability of molecular oxygen to react with methyl radical. Here, the reaction of P450CLA with tert-BuOOH was investigated by both direct EPR of heme iron at liquid helium temperature and by using spin trapping for the assignment of primary and secondary free radical species.
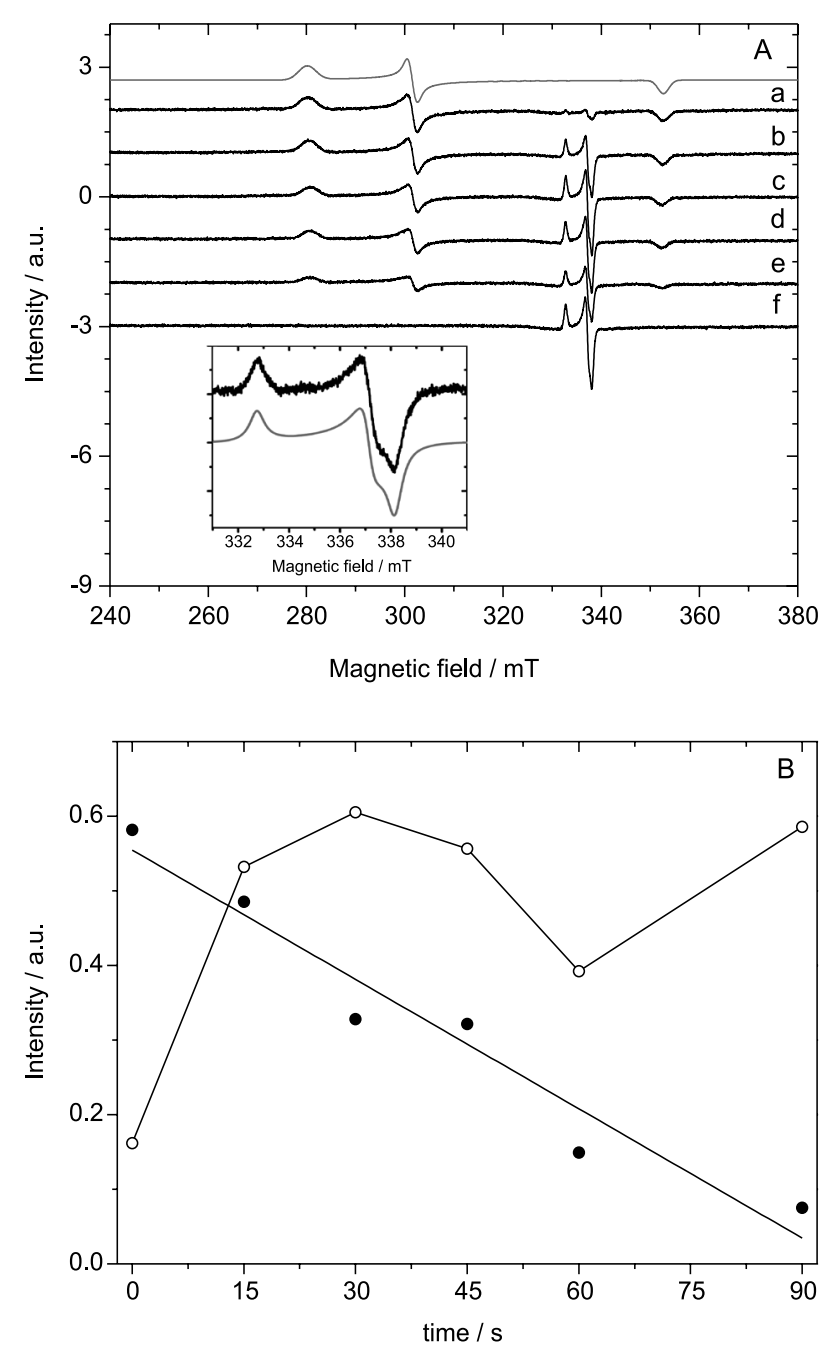

Figure 3. Continuous wave EPR spectra of P450CLA in the course of the reaction with tert-BuOOH. (A) P450CLA was studied using EPR before and after the addition of tert-BuOOH. Line a corresponds to the spectrum of P450CLA before the addition of tert $\mathrm{BuOOH}$ and the gray line the simulated spectrum with $g=2.417,2.245,1.919$ assigned to the ferric low-spin P450CLA heme iron. The set of lines around $330 \mathrm{mT}$ obtained after the addition of tert-BuOOH is assigned to a radical formed as shown in the inset (the thin line in the inset is the spectral simulation with $g=2.0348,2.0083,2.0022$ ). The spectrum showed as line $f$ was obtained after thaw and mixing. (B) Linear decrease of $\mathrm{Fe}^{3+} \mathrm{EPR}$ signal intensity (closed circle) with concomitant non-linear EPR radical formation (open circle).

Figure 3 shows that the addition of tert $\mathrm{BuOOH}$ to the P450CLA solution led to progressive disappearance of the heme iron EPR signal with concomitant appearance of a free radical signal $(g=2.0348,2.0083,2.0022)$ assigned to a peroxyl radical (Figure 3A, lines b to $\mathrm{d}$ and inset). The disappearance of the heme $\mathrm{Fe}^{3+}$ signal is consistent with the conversion of the resting enzyme to the high valence oxoferryl form $\left(\mathrm{Fe}^{\mathrm{IV}}=\mathrm{O}\right)$ since a heterolytic cleavage of tert-BuOOH would result in the formation of a ferryl $\left(\mathrm{Fe}^{\mathrm{IV}}\right)$-oxo $\pi$-cation radical, which would have a detectable distinctive EPR signal. While the heme iron EPR signal 


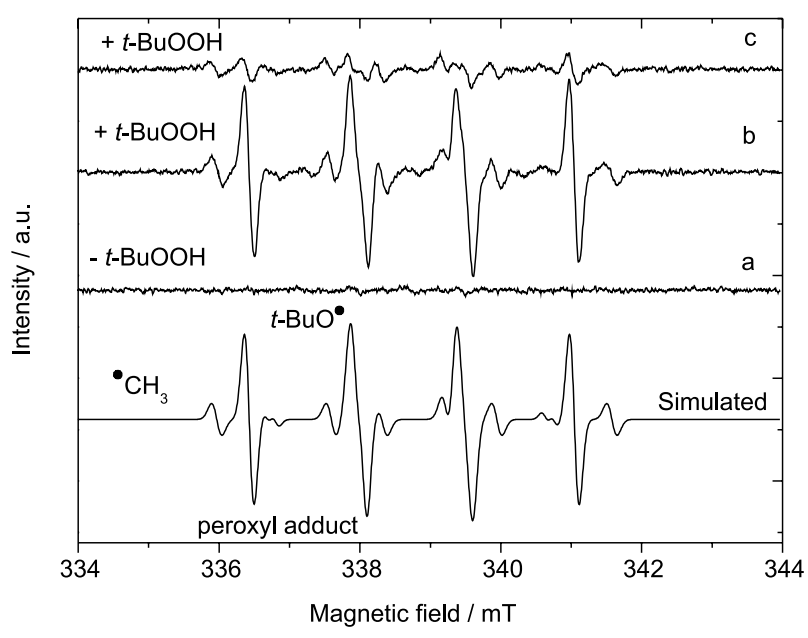

Figure 4. EPR of radical adducts from the P450CLA/tert-BuOOH reaction, spin trapped using DMPO. DMPO spin trap was added to P450CLA samples at two distinct concentrations $\left(650 \times 10^{-3}\right.$ and $160 \times 10^{-3} \mathrm{~mol} \mathrm{~L}^{-1}$, lines $\mathrm{b}$ and $\mathrm{c}$, respectively). Line a represents the spectrum obtained in the presence of DMPO $650 \times 10^{-3} \mathrm{~mol} \mathrm{~L}^{-1}$ and the absence of tert-BuOOH. Radical formation was initiated by the addition of $375 \times 10^{-3} \mathrm{~mol} \mathrm{~L}^{-1}$ tert $-\mathrm{BuOOH}$ to the samples. Three radical adducts were identified: the alcoxyl adduct (tert-BuO*), with $\mathrm{g}=2.0059, \mathrm{a}_{\mathrm{N}}=1.500 \mathrm{mT}$, $\mathrm{a}^{\beta}{ }_{\mathrm{H}}=1.615 \mathrm{mT}$; the methyl adduct $\left({ }^{\circ} \mathrm{CH}_{3}\right), \mathrm{g}=2.0057, \mathrm{a}_{\mathrm{N}}=1.630 \mathrm{mT}$, $\mathrm{a}^{\beta}{ }_{\mathrm{H}}=2.350 \mathrm{mT}$ and the peroxyl adduct, $\mathrm{g}=2.0058, \mathrm{a}_{\mathrm{N}}=1.400 \mathrm{mT}$, $\mathrm{a}^{\beta}{ }_{\mathrm{H}}=1.160 \mathrm{mT}, \mathrm{a}_{\mathrm{H}}^{\gamma}=0.125 \mathrm{mT}$ and indicated in the simulated spectrum. At the highest DMPO concentration used, the alcoxyl (tert-BuO*) signal was accentuated and predominated.

decayed linearly along the time course reaction ( $90 \mathrm{~s})$, the peroxyl radical signal exhibited a hyperbolic growing up to $30 \mathrm{~s}$ reaction and decayed at subsequent times (Figure 3B). The shaking of the sample at $60 \mathrm{~s}$ reaction time restored the maximal intensity of the peroxyl EPR signal (Figure 3A, line f). This behavior can be rationalized by the molecular oxygen dependence for the peroxyl radical formation. As mentioned by Barr et al. ${ }^{29}$ who previously investigated the reaction of rabbit $\mathrm{P} 450$ with cumene hydroperoxide by using EPR spin trapping technique, the reaction involves the initial homolytic scission of the peroxide $\mathrm{O}-\mathrm{O}$ bond to produce the cumoxyl radical. In the following, the $\beta$-scission of the cumoxyl radical produced methyl radical that, in turn, produced peroxyl radical by reaction with molecular oxygen. This proposal was corroborated by the absence of peroxyl-DMPO adduct signal in the absence of molecular oxygen. The authors concluded that the DMPO peroxyl radical adduct detected in the presence of oxygen was due to the methylperoxyl radical formed. Similarly, in the system presented here, the $\beta$-scission of the butyloxyl radical produced methyl radical that reacted with molecular oxygen to produce methylperoxyl free radical. The molecular oxygen depletion was responsible for the EPR signal decay after $30 \mathrm{~s}$ and the shaking of the sample restored the signal intensity by replacing the exhausted reagent.
The identity of primary and secondary radicals produced by the reaction of P450CLA tert-BuOOH was investigated by EPR in the presence of two concentrations of the spin trapping DMPO: $160 \times 10^{-3} \mathrm{~mol} \mathrm{~L}^{-1}$ and $650 \times 10^{-3} \mathrm{~mol} \mathrm{~L}^{-1}$ (Figure 4).

The EPR spectra obtained with $650 \times 10^{-3} \mathrm{~mol} \mathrm{~L}^{-1}$ DMPO in the presence of tert-BuOOH was a composite of three different free radicals (Figure 4, line b) identified by simulation as tert-BuO', ${ }^{\circ} \mathrm{CH}_{3}$ and a peroxyl radical. A simulation of the spectrum of the DMPO-trapped adducts provided the following EPR parameters: $\mathrm{g}=2.0059$, $\mathrm{a}_{\mathrm{N}}=1.500 \mathrm{mT}$ and $\mathrm{a}^{\beta}{ }_{\mathrm{H}}=1.615 \mathrm{mT}$ for the alcoxyl adduct; $\mathrm{g}=2.0057, \mathrm{a}_{\mathrm{N}}=1.630 \mathrm{mT}$ and $\mathrm{a}_{\mathrm{H}}{ }=2.350 \mathrm{mT}$ for the methyl adduct and $\mathrm{g}=2.0058, \mathrm{a}_{\mathrm{N}}=1.400 \mathrm{mT}$, $\mathrm{a}_{\mathrm{H}}{ }_{\mathrm{H}}=1.160 \mathrm{mT}$ and $\mathrm{a}_{\mathrm{H}}^{\gamma}=0.125 \mathrm{mT}$ for the peroxyl adduct. The same EPR signals were present at $160 \mathrm{mmol} \mathrm{L}^{-1}$ DMPO (Figure 4, line c); however, while no significant decrease of methyl and peroxyl radical signals was observed, the signal assigned to butyloxyl radical decreased around fivefold consistent with tert-BuO ${ }^{*}$ as the primary radical produced by homolytic scission of peroxide $\mathrm{O}-\mathrm{O}$ bond.

\section{Conclusions}

The present study shows, for the first time, a spectroscopic characterization of P450CLA that was consistent with a $\mathrm{P} 450$ protein and also with the well-known assignment of orf10 as a P450 gene. ${ }^{1-4}$ In addition the affinity for exogenous ligands mimicking the structure of metabolites of clavulanic acid pathway and reactivity with organic peroxide were also characterized. In this regard, special attention has been paid to P450s catalysis in view of a diversity of potential applications for the enzyme such as cost-effective synthesis, the degradation of toxic compounds and many other uses. Therefore, rational engineering of P450s using techniques such as in vitro evolution and site-directed mutagenesis will be required to meet these objectives, ${ }^{30}$ allowing efficient tailor-made $\mathrm{P} 450$ s to become available. Such approaches could be also applied to CYP105M1 to obtain new types of secondary metabolites or to increase clavulanic acid production. Orf10-disrupted mutants of S. clavuligerus have been shown to lack clavulanic acid production. Such mutants restored their clavulanic acid production by using a plasmid carrying a functional copy of orf10.,31,32 Transformed S. clavuligerus cells carrying multiple orf10 and orf 11 copies have shown more than $100 \%$ increase in clavulanic acid production over non-transformed cells ${ }^{5}$ and this result indicates the potential application of the enzymatic function of CYP105M1 that could be improved by engineering a more efficient enzyme or replacing the original one. 


\section{Supplementary Information}

Supplementary Information shows P450CAM primary structure, SDS PAGE of P450CAM and far UV CD of the purified protein. This material is available free of charge at http://jbcs.sbq.org.br, as PDF file.

\section{Acknowledgements}

The authors are grateful to Andressa Patricia Alves Pinto and Derminda Isabel de Moraes from the Grupo de Biofísica Molecular "Sergio Mascarenhas" laboratory technical team for their support and to Dr. Heloisa Sobreiro Selistre-de-Araújo from Laboratório de Bioquímica e Biologia Molecular, Departamento de Ciências Fisiológicas, UFSCar, for providing antibodies.

This work was supported by the Fundação de Amparo à Pesquisa do Estado de São Paulo (FAPESP, processes No. 06/59693-1 and 08/04948-0), PRONEX/FAPESP and Conselho Nacional de Desenvolvimento Científico e Tecnológico (CNPq, processes No. 474059/2008-1 and 475235/2010-0).

\section{References}

1. Jensen, S. E.; Paradkar, A. S.; Antonie Van Leeuwenhoek 1999 , $75,1253$.

2. Jensen, S. E.; Paradkar, A. S.; Mosher, R. H.; Anders, C.; Beatty, P. H.; Brumlik, M. J.; Griffin, A.; Barton, B.; Antimicrob. Agents Chemother. 2004, 48, 192.

3. Liras, P.; Rodriguez-Garcia, A.; Appl. Microbiol. Biotechnol. 2000, 54, 467

4. Li, R.; Khaleeli, N.; Townsend, C. A.; J. Bacteriol. 2000, 182, 4087.

5. Mellado, E.; Lorenzana, L. M.; Rodriguez-Saiz, M.; Diez, B.; Liras, P.; Barredo, J. L.; Microbiology 2002, 148, 1427.

6. Howarth, T. F.; Brown, A. G.; King, T. J.; J. Chem. Soc. Chem. Commun. 1976, 266

7. Parajuli, N.; Basnet, D. B.; Lee, H. C.; Sohng, J. K.; Liou, K.; Arch. Biochem. Biophys. 2004, 425, 233.

8. Munro, A. W.; Girvan, H. M.; McLean, K. J.; Nat. Prod. Rep. 2007, 24, 585.

9. http://drnelson.uthsc.edu/biblioE.html\#105E accessed in March 2012.

10. Zhao, B.; Waterman, M. R.; Drug Metab. Rev. 2007, 39, 343.

11. Ausubel, F. M.; Brent, R.; Moore, D.; Short Protocols in Molecular Biology: A Compendium of Methods from Current Protocols in Molecular Biology, $5^{\text {th }}$ ed.; Wiley: New York, 2002.

12. Sreerama, N.; Venyaminov, S. Y.; Woody, R. W.; Anal. Biochem. 2001, 299, 271.

13. Sreerama, N.; Woody, R. W.; Methods Enzymol. 2004, 383, 318.
14. Pimenta, D. C.; Nantes, I. L.; De Souza, E. S.; Le Bonniec, B.; Ito, A. S.; Tersariol, I. L. S.; Oliveira, V.; Juliano, M. A.; Juliano, L; Biochem. J. 2002, 366, 435

15. Sigrist, C. J.; Cerutti, L.; Hulo, N.; Gattiker, A.; Falquet, L.; Pagni, M.; Bairoch, A.; Bucher, P.; Brief. Bioinform. 2002, 3, 265.

16. Wilkins, M. R.; Gasteiger, E.; Bairoch, A.; Sanchez, J. C.; Williams, K. L.; Appel, R. D.; Hochstrasser, D. F.; Methods Mol. Biol. 1999, 112, 531.

17. Sugimoto, H.; Shinkyo, R.; Hayashi, K.; Yoneda, S.; Yamada, M.; Kamakura, M.; Ikushiro, S.; Shiro, Y.; Sakaki, T.; Biochemistry 2008, 47, 4017.

18. Altschul, S. F.; Madden, T. L.; Schaffer, A. A.; Zhang, J.; Zhang, Z.; Miller, W.; Lipman, D. J.; Nucleic Acids Res. 1997, 25,3389

19. Dawson, J. H.; Andersson, L. A.; Sono, M.; J. Biol Chem. 1982, 257,3606 .

20. Neese, F.; Solomon, E. I.; Inorg. Chem. 1999, 38, 1847.

21. Nantes, I. L.; Crespilho, F. N.; Mugnol, K. C. U.; Chaves, J. C. A.; Luz, R. A. S.; Nascimento, O. R.; Pinto, S. M. S. In Circular Dichroism: Theory and Spectroscopy; Rodgers, D. S., ed.; Nova Science Publishers, Inc.: New York, 2012, ch. 9, ISBN 978-1-61122-522-8.

22. Dawson, J. H.; Andersson, L. A.; Sono, M.; J. Biol. Chem. 1983, $258,13637$.

23. Tudzynski, B.; Mihlan, M.; Rojas, M. C.; Linnemannsto, P.; Gaskin, P.; Hedden, P.; J. Biol. Chem. 2003, 278, 28635.

24. Barr, I.; Smith, A. T.; Senturia, R.; Chen, Y.; Scheidemantle, B. D.; Burstyn, J. N.; Guo, F.; Biol. Chem. 2011, 286, 16716.

25. Gouterman, M. In The Porphyrins, vol. 3; Dolphin, D., ed.; Academic Press: New York, 1978.

26. Hanson, L. K.; Eaton, W. A.; Aligar, S. G.; Gunsalus, I. C.; Gouterman, M.; Connell, C. R.; J. Am. Chem. Soc. 1976, 98, 2672.

27. Jung, C.; Ristau, O.; Chem. Phys. Lett. 1977, 49, 103.

28. Hocking, R. K.; Wasinger, E. C.; Yan1 Y-L.; deGroot, F. M. F. F.; Walker, A.; Hodgson, K. O.; Hedman, B.; Solomon, E. I.; J. Am. Chem. Soc. 2007, 129, 113.

29. Barr, D. P.; Martin, M. V.; Guengerich, F. P.; Mason, R. P.; Chem. Res. Toxicol. 1996, 9, 318.

30. Urlacher, V.; Schmid, R. D.; Curr. Opin. Biotechnol. 2002, 13, 557.

31. Kellner, D. G.; Maves, S. A.; Sligar, S. G.; Curr. Opin. Biotechnol. 1997, 8, 274.

32. De la Fuente, A.; Lorenzana, L. M.; Martin, J. F.; Liras, P.; J. Bacteriol. 2002, 184, 6559 .

Submitted: September 28, 2011

Published online: April 19, 2012

FAPESP has sponsored the publication of this article. 